$01,03,13$

\title{
Особенности перемагничивания обменно-связанных пленочных структур Tb-Co/FeNi в температурном интервале, включающем точку компенсации ферримагнитного слоя
}

\author{
(C) А.В. Свалов ${ }^{1}$, В.Н. Лепаловский ${ }^{1}$, Е.А. Степанова ${ }^{1}$, И.А. Макарочкин ${ }^{1}$, В.О. Васьковский ${ }^{1,2}$, \\ A. Larañaga ${ }^{3}$, Г.В. Курляндская ${ }^{1,3}$ \\ ${ }^{1}$ Институт естественных наук и математики, Уральский фредеральный университет им. Б.Н. Ельцина, \\ Екатеринбург, Россия \\ ${ }^{2}$ Институт фризики металлов им. М.Н. Михеева РАН, \\ Екатеринбург, Россия \\ ${ }^{3}$ Университет Страны Басков, \\ Бильбао, Испания \\ E-mail: andrey.svalov@urfu.ru
}

Поступила в Редакцию 9 апреля 2021 г.

В окончательной редакции 9 апреля 2021 г.

Принята к публикации 19 апреля 2021 г.

Представлены результаты исследования магнитных свойств обменно-связанных пленочных структур $\mathrm{Tb}-\mathrm{Co} / \mathrm{FeNi}$, полученных методом магнетронного распыления, в широком интервале температур. Показано, что уменьшение энергии Зеемана при приближении к температуре компенсации ферримагнитного слоя сопровождается изменением последовательности перемагничивания слоев. Эффективность межслойного обменного взаимодействия слабо изменяется с температурой.

Ключевые слова: многослойные пленки, межслойное обменное взаимодействие, обменное смещение, ферримагнетизм, магнитная компенсация, пермаллой.

DOI: $10.21883 /$ FTT.2021.09.51238.34H

\section{1. Введение}

Одним из ключевых моментов для создания тонкопленочных устройств спинтроники, таких как магнитные датчики или устройства оперативной памяти, является возможность контроля ориентации магнитного момента ферромагнитного слоя. Чаще всего для этого используют гетероструктуры антиферромагнетик/ферромагнетик (АФМ/ФМ), в которых обменная связь между слоями является причиной возникновения однонаправленной анизотропии [1]. Это явление называют также обменным смещением, так как петля гистерезиса ФМ-слоя оказывается смещенной относительно нулевого поля. Наличие обменного смещения позволяет „закрепить“ магнитный момент ФМ-слоя, т.е. препятствовать его перемагничиванию в некотором интервале внешнего магнитного поля, превышающем величину коэрцитивной силы слоя. Преимуществом АФМ как „закрепляющего“ слоя является отсутствие у него суммарного магнитного момента, что обеспечивает устойчивость к внешнему магнитному полю. Однако в последнее время в качестве эффективного источника внутреннего магнитного смещения в слоистых обменно-связанных структурах успешно используются ферримагнитные пленки аморфных сплавов переходных металлов $(\Pi \mathrm{M}=\mathrm{Co}, \mathrm{Fe})$ и тяжелых редкоземельных элементов (P3= Tb, Dy) [2-4]. Большая величина магнитной анизотропии $\mathrm{Tb}$ и Dy является причиной большой коэрцитивной силы этих сплавов.
В пленочной системе Р3-ПМ/ФМ в интервале полей, не превышающих коэрцитивную силу Р3-ПМ-слоя, петля гистерезиса ФМ-слоя также оказывается смещенной.

Смещение петли гистерезиса принято характеризовать величиной поля обменного смещения $\left(H_{\mathrm{eb}}\right)$. В пленках АФМ/ФМ смещение, как правило, „отрицательно“, т.е. петля смещена в направлении, противоположном направлению поля, в котором формировалась однонаправленная анизотропия. При повышении температуры образца $H_{\text {eb }}$ уменьшается, и обменное смещение исчезает при приближении к температуре Нееля АФМ-слоя. Температура, при которой обменное смещение (однонаправленная анизотропия) исчезает, получило название температуры блокировки $\left(T_{\mathrm{b}}\right)$. Для пленочных систем Р3-ПМ/ФМ величина $T_{\mathrm{b}}$ может достигать $250^{\circ} \mathrm{C}$, превосходя аналогичную величину для пленок АФМ/ФМ примерно на $100^{\circ} \mathrm{C}[5]$. Для возникновения обменного смещения в системе АФМ/ФМ слой АФМ должен обладать строго определенным типом кристаллической решетки и острой текстурой [6], тогда как аморфное состояние Р3-ПМ-слоя снимает подобное условие, что является еще одним преимуществом ферримагнитного „закрепляющего“ слоя.

В сплавах Р3-ПМ, содержащих тяжелые редкоземельные элементы, обменное взаимодействие выстраивает антипараллельно магнитные моменты Р3- и ПМ-подрешеток. Как правило, пленки Р3-ПМ обладают выраженной температурной зависимостью спонтанной 
намагниченности. Кроме того, при определенном соотношении состава и температуры образца в пленке может реализоваться состояние магнитной компенсации, при котором спонтанная намагниченность близка к нулю, так как магнитные моменты подрешеток Р3 и ПМ становятся равными по величине и уравновешивают друг друга. Данную температуру обозначают как температуру компенсации $\left(T_{\text {comp }}\right)$ [7]. При $T<T_{\text {comp }}$ преобладает магнитный момент подрешетки Р3, который, как и суммарный магнитный момент образца, выстраивается вдоль направления внешнего магнитного поля. При $T>T_{\text {comp }}$ определяющим является магнитный момент подрешетки ПМ. Поэтому в системе РЗ-ПМ/ФМ может реализовываться как „отрицательное“, так и „положительное“ обменное смещение. Это было продемонстрировано ранее на сериях образцов, в которых смена преобладающей магнитной подрешетки в слое Р3-ПМ достигалась путем изменения химического состава образцов [2] или варьированием процедуры охлаждения образца во внешнем магнитном поле [8-10]. С точки зрения разработки устройств спинтроники, работающих в широком интервале температур, необходимо иметь данные и о возможности смены знака обменного смещения при изменении преобладающей магнитной подрешетки в слое Р3-ПМ за счет изменения температуры образца при переходе через $T_{\text {comp. }}$

Остается открытым вопрос о том, какая из магнитных подрешеток слоя Р3-ПМ вносит основной вклад в обеспечение обменного смещения в структурах типа Р3-ПМ/ФМ. С одной стороны, хорошо известно, что обменное взаимодействие между атомами переходных металлов примерно на порядок превосходит аналогичную величину для пары переходный металл-редкая земля [11]. С другой стороны, межслойное взаимодействие пропорционально величине намагниченностей, а при низких температурах намагниченность подрешетки P3 может заметно превосходить намагниченность подрешетки ПМ [7,11].

Пленки пермаллоя являются одним из самых используемых материалов в устройствах спинтроники [12,13]. Регулируемая путем подбора химического состава температурная зависимость магнитных свойств ферримагнитных пленок может обеспечить дополнительные возможности при разработке устройств спинтроники на основе систем РЗ-ПМ/ФМ. В настоящей работе представлены результаты исследования магнитных свойств обменно-связанных пленочных структур $\mathrm{Tb}-\mathrm{Co} / \mathrm{FeNi}$ в широком интервале температур, включающем температуру компенсации ферримагнитного слоя $\mathrm{Tb}-\mathrm{Co}$.

\section{2. Методика исследований}

Пленки $\mathrm{Tb}-\mathrm{Co}, \mathrm{Fe}_{19} \mathrm{Ni}_{81}$ и многослойные образцы $\mathrm{Ta}(5 \mathrm{~nm}) / \mathrm{Tb}-\mathrm{Co}(27 \mathrm{~nm}) / \mathrm{FeNi}(40 \mathrm{~nm}) / \mathrm{Ta}(5 \mathrm{~nm})$ были осаждены на стеклянные подложки методом магнетронного распыления соответствующих мишеней. Слои $\mathrm{Tb}-\mathrm{Co}$ получены путем сораспыления однокомпонентных мишеней Тb и Со. Слои Та осуществляли защитную функцию. Химический состав пленок $\mathrm{Tb}-\mathrm{Co}$ определялся на ренгенофлуоресцентном спектрометре Nanohunter и составил $\mathrm{Tb}_{19.3} \mathrm{Co}_{80.7}$. В процессе осаждения пленок в плоскости подложек прикладывалось постоянное магнитное поле напряженностью 250 Э для создания в пленках наведенной одноосной магнитной анизотропии. Рентгенографические исследования образцов были выполнены на дифрактометрах D8-Advance и Rigaku Smartlab, излучение $\mathrm{Cu}-\mathrm{K} \alpha$. Измерения магнитных свойств пленок в интервале температур от 5 до $300 \mathrm{~K}$ проводились на измерительном комплексе MPMS-7XL.

\section{3. Полученные результаты}

На рис. 1, $a$ приведена дифрактограмма пленки $\mathrm{Ta} / \mathrm{Tb}-\mathrm{Co} / \mathrm{FeNi} / \mathrm{Ta}$. Рефлекс около $2 \theta \approx 44.3^{\circ}$ соответствует линии (111) гранецентрированной кубической решетки пермаллоя. Средний размер кристаллитов, определенный с помощью формулы Шеррера, составил $20 \mathrm{~nm}$. Отсутствие других линий на дифрактограмме свидетельствует как о наличии текстуры в слое $\mathrm{FeNi}$, так и рентгено-аморфном состоянии слоев $\mathrm{Tb}-\mathrm{Co}$ и Та. На рис. $1, b$ показаны данные рентгеновской рефлектометрии для этого образца. На их основе были уточнены толщины слоев $\mathrm{Tb}-\mathrm{Co}$ и $\mathrm{FeNi}$, которые согласуются с номинальными величинами.

Петли гистерезиса, измеренные в разных направлениях в плоскости образцов как однослойных $\mathrm{Tb}-\mathrm{Co}$
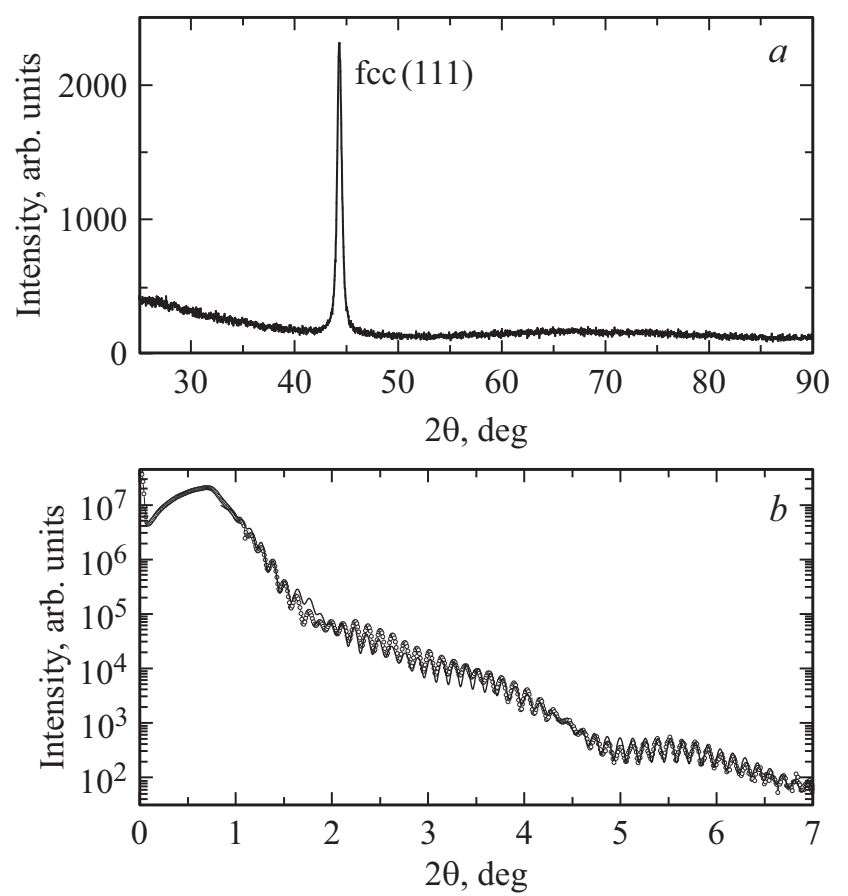

Рис. 1. Дифрактограмма $(a)$ и данные рентгеновской рефлектометрии (символы - экспериментальная кривая, сплошная линия - рассчитанная кривая) (b) пленки $\mathrm{Ta} / \mathrm{Tb}-\mathrm{Co} / \mathrm{FeNi} / \mathrm{Ta}$. 

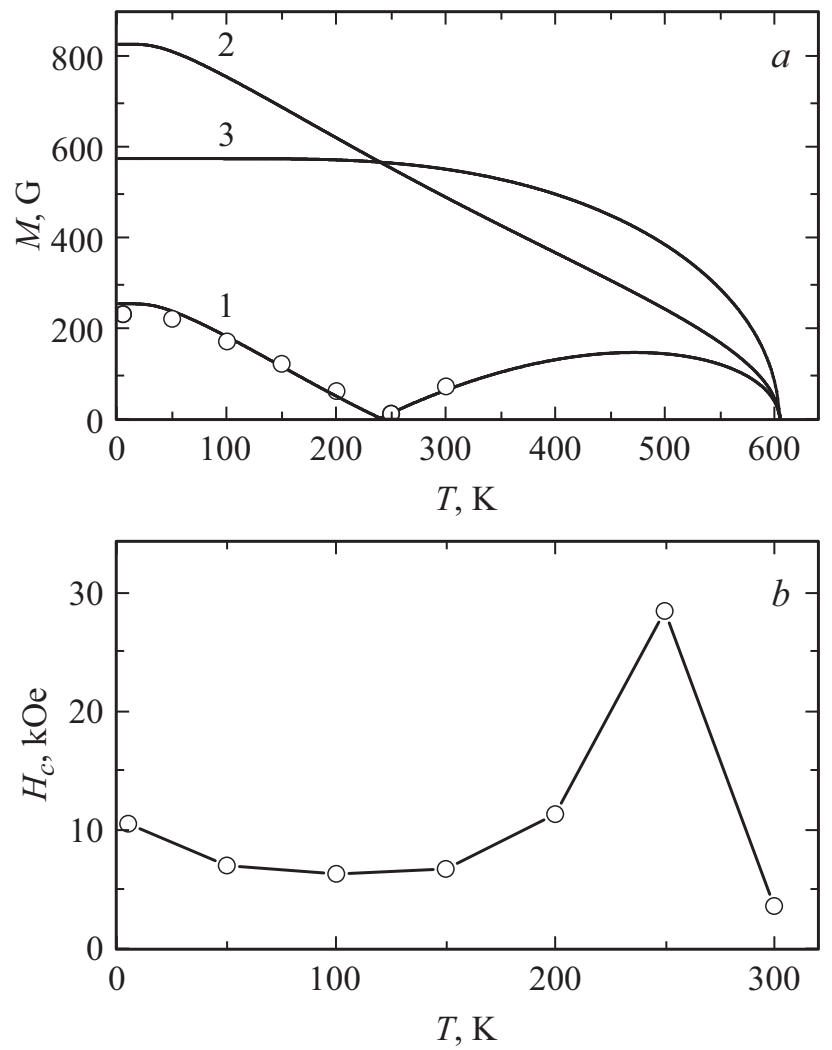

Рис. 2. Температурные зависимости спонтанной намагниченности $(a)$ и коэрцитивной силы $(b)$ для пленки $\mathrm{Tb}_{19.3} \mathrm{Co}_{80.7}$. Точки - экспериментальные данные, линии - рассчитанные кривые суммарной намагниченности образца (1) и намагниченностей подрешеток $\mathrm{Tb}(2)$ и Сo (3).

и $\mathrm{FeNi}$, так и двухслойных пленок $\mathrm{Tb}-\mathrm{Co} / \mathrm{FeNi}$, свидетельствуют о том, что в пленках сформировалась наведенная магнитная анизотропия, ось легкого намагничивания (ОЛН) совпадает с направлением технологического магнитного поля, присутствовавшего во время напыления. Температурная зависимость спонтанной намагниченности однослойной пленки $\mathrm{Tb}-\mathrm{Co}$ была определена из петель гистерезиса, измеренных при разных температурах (рис. 2,a). Она хорошо описываются в рамках двухподрешеточной модели коллинеарного ферримагнетизма Нееля [11].

На рис. 2, a также представлены температурные зависимости намагниченностей подрешеток Тb и Со. Видно, что для пленки $\mathrm{Tb}_{19.3} \mathrm{Co}_{80.7} T_{\text {comp }} \approx 240 \mathrm{~K}$. Температурная зависимость коэрцитивной силы данной пленки имеет характерный для ферримагнетиков вид с максимумом вблизи $T_{\text {comp }}$ (рис. $2, b$ ). Измеренные при разных температурах на однослойной пленке FeNi петли гистерезиса показали, что намагниченность слоев пермаллоя слабо изменяется с температурой и составляет примерно $800 \mathrm{G}$, а коэрцитивная сила не превышает 5 Ое.

На рис. 3 показаны петли гистерезиса, измеренные вдоль ОЛН на пленке $\mathrm{Tb}-\mathrm{Co} / \mathrm{FeNi}$ при разных температурах. Поведение в магнитном поле таких систем определяется балансом энергий Зеемана, магнитной анизотропии и межслойного обмена. За исключением случая при $T=250 \mathrm{~K}$, ступенчатая форма петель свидетельствует о послойном перемагничивании пленки. Учитывая намагниченность и толщину слоев, соответствующие им петли устанавливаются однозначно. При $T=5 \mathrm{~K}$ в суммарном магнитном моменте слоя $\mathrm{Tb}-\mathrm{Co}$ доминирует момент редкоземельной компоненты, и, как уже отмечалось, он противонаправлен моменту подрешетки Со, который, в свою очередь, ферромагнитно связан с магнитным моментом слоя $\mathrm{FeNi}$. Таким образом, в отсутствии внешнего магнитного поля магнитные моменты слоев $\mathrm{Tb}-\mathrm{Co}$ и $\mathrm{FeNi}$ упорядочены антипараллельно (рис. 3,e). Сильное внешнее поле выстраивает магнитные моменты слоев параллельно друг другу (рис. 3,e). При этом в межслойной области образуется магнитная неоднородность типа доменной границы (на схемах обозначена крестиками). Ее энергию можно оценить, используя известное выражение [14]:

$$
\sigma_{w}=4\left(A K_{u}\right)^{1 / 2}
$$

где $A-$ константа обменного взаимодействия, $K_{u}-$ константа анизотропии. Для пленок FeNi в литературе можно встретить заметно различающиеся величины $A$ от $0.65 \cdot 10^{-6}$ до $2.6 \cdot 10^{-6} \mathrm{erg} / \mathrm{cm}[15-17]$. Наши измерения спин-волнового резонанса на однослойной пленке $\mathrm{FeNi}$ дают величину $A=1.2 \cdot 10^{-6} \mathrm{erg} / \mathrm{cm}$. Именно ее мы использовали вместе с $K_{u}=2 \cdot 10^{3} \mathrm{erg} / \mathrm{cm}^{3}$ при оценке величины $\sigma_{w}$ в слое $\mathrm{FeNi}$, которая в итоге составила $0.2 \mathrm{erg} / \mathrm{cm}^{2}$. При оценке энергии подобной границы в слое $\mathrm{Tb}-\mathrm{Co}$ были использованы величины $A=2 \cdot 10^{-7} \mathrm{erg} / \mathrm{cm}[18]$ и $K_{u}=2 \cdot 10^{6} \mathrm{erg} / \mathrm{cm}^{3}$ [19], что приводит к величине $\sigma_{w}=2.5 \mathrm{erg} / \mathrm{cm}^{2}$. Сравнение двух величин $\sigma_{w}$ дает основание предполагать, что граница формируется в слое $\mathrm{FeNi}$.

При $T=5 \mathrm{~K}$ поведение пленки $\mathrm{Tb}-\mathrm{Co} / \mathrm{FeNi}$ во многом аналогично поведению „обменной“ или „спиновой пружины“ - обменносвязанной пленочной системы, состоящей из магнитожесткого и магнитомягкого слоев [20]. Одним из таких признаков является смещенная безгистерезисная частная петля перемагничивания магнитомягкого слоя (вставка на рис. 3,a). В „классическом“ варианте „спиновой пружины“, например, $\mathrm{SmCo} / \mathrm{Fe}[21]$, где оба слоя ферромагнитны, межслойная магнитная граница возникает при перемагничивании магнитомягкого слоя и исчезает, когда при дальнейшем увеличении поля перемагничивается магнитожесткий слой, и магнитные моменты слоев становятся сонаправленными. В нашем случае, наоборот, параллельное выстраивание моментов слоев сопровождается возникновением и сжатием межслойной границы (рис. 3, $a$ и $3, e)$. Уменьшение поля сопровождается разворотом магнитных моментов внутри слоя $\mathrm{FeNi}$ и исчезновением межслойной магнитной границы. Смена направления внешнего поля на противоположное и его увеличение стабилизирует ориентацию магнитного момента слоя 

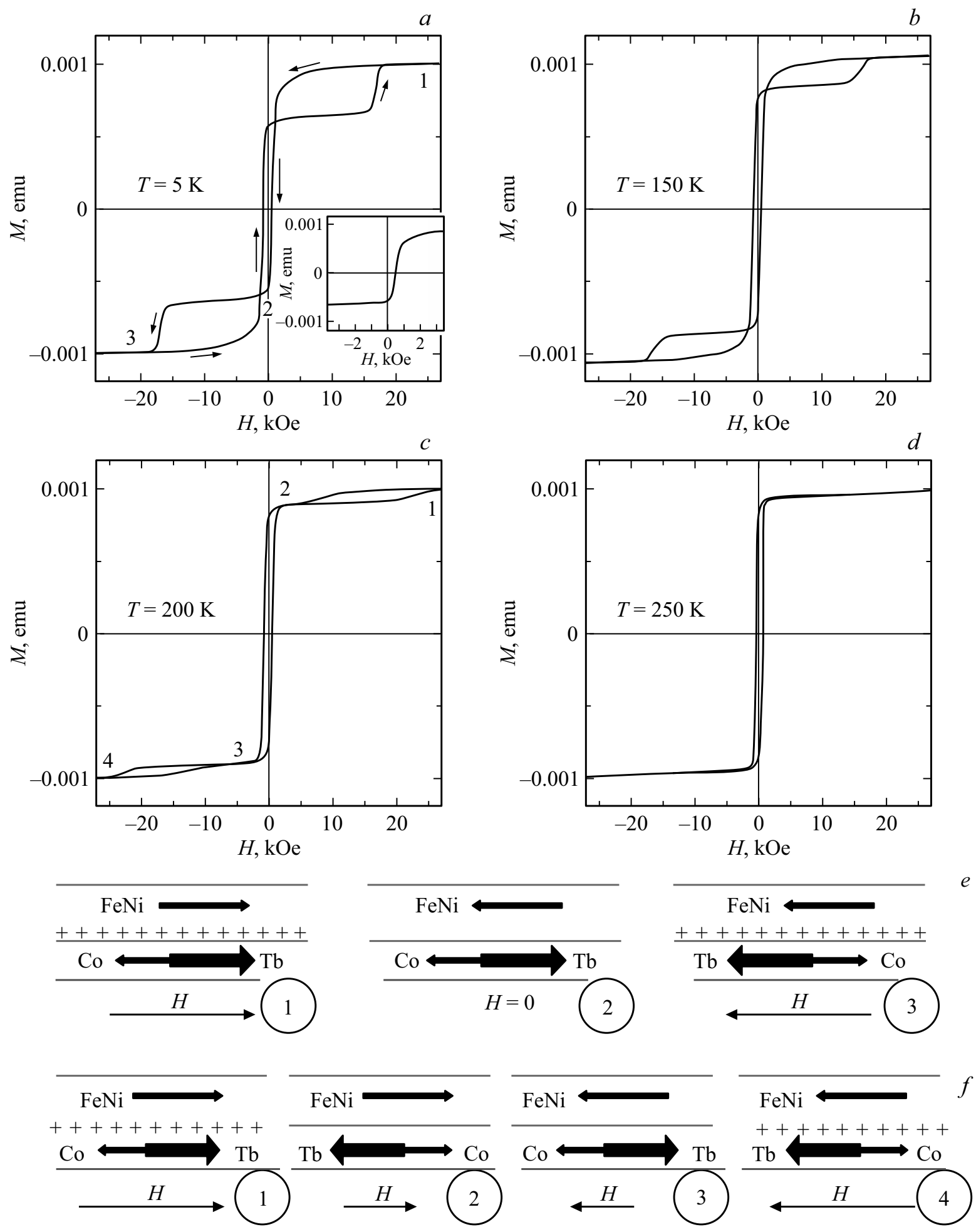

Рис. 3. Петли гистерезиса, измеренные вдоль ОЛН на пленке Тb-Co/FeNi при разных температурах $(a-d)$; схематическое изображение различных стадий перемагничивания пленки при разных температурах $(e-5 \mathrm{~K} ; f-200 \mathrm{~K})$. На вставке показана частная петля гистерезиса слоя $\mathrm{FeNi.}$

$\mathrm{FeNi}$, но при определенной величине приводит к перемагничиванию слоя $\mathrm{Tb}-\mathrm{Co}$. Форма соответствующей петли гистерезиса заставляет предположить, что этот процесс осуществляется путем зарождения доменов об- ратной фазы и их роста за счет бокового движения доменных границ, при этом в слое FeNi снова формируется магнитная граница типа доменной стенки Блоха. Справедливость данного механизма перемагничивания была 
подтверждена прямым наблюдением изменения доменной структуры в двухслойной системе $\mathrm{SmFe} / \mathrm{FeNi}$ [22].

Увеличение температуры образца сопровождается уменьшением момента слоя $\mathrm{Tb}-\mathrm{Co}$ и, следовательно, его энергии во внешнем поле, а вблизи $T_{\text {comp энергия }}$ Зеемана слоя $\mathrm{Tb}-$ Со становится меньше, чем у слоя FeNi. Это приводит к смене последовательности перемагничивания слоев: при уменьшении поля сначала перемагничивается слой $\mathrm{Tb}-\mathrm{Co}$, и магнитные моменты слоев выстраиваются антипараллельно (рис. 3, $c$ и $f$ ), в относительно слабом поле противоположной направленности система $\mathrm{Tb}-\mathrm{Co} / \mathrm{FeNi}$ перемагничивается как единое целое, а дальнейшее увеличение поля приводит к перемагничиванию слоя $\mathrm{Tb}-\mathrm{Co}$ и возникновению межслойной границы.

При всем различии смещенных петель гистерезиса слоев $\mathrm{FeNi}$ и $\mathrm{Tb}-\mathrm{Co}$ (рис. 3, $a$ и $c$ ) они обе смещены вправо от нулевого поля, то есть знак обменного смещения не изменился, а само смещение обусловлено межслойным обменным взаимодействием, эффективность которого характеризуется величиной константы поверхностного межслойного взаимодействия $(j)$, которую можно оценить, используя известное выражение

$$
H_{\mathrm{eb}}=j / M_{\mathrm{b}} t_{\mathrm{b}}
$$

где $M_{\mathrm{b}}$ и $t_{\mathrm{b}}$ - намагниченность и толщина слоя, который характеризуется смещенной петлей [6]. При $T=5 \mathrm{~K}$ $H_{\mathrm{ex}}=600 \mathrm{Oe}$, используя параметры слоя $\mathrm{FeNi}$, получаем $j=1.9 \mathrm{erg} / \mathrm{cm}^{2}$. При $T=200 \mathrm{~K} H_{\mathrm{eb}}=15.4 \mathrm{kOe}$, $M_{\mathrm{Tb}-\mathrm{Co}}=60 \mathrm{G}$ и $j=2.5 \mathrm{erg} / \mathrm{cm}^{2}$. Известно, что обменное взаимодействие между магнитными моментами ПМ атомов на порядок сильнее, чем в атомных парах Р3-ПМ [11], поэтому можно ожидать, что обменная связь в системе $\mathrm{Tb}-\mathrm{Co} / \mathrm{FeNi}$ в основном определяется взаимодействием моментов слоя $\mathrm{FeNi}$ и подрешетки Co слоя $\mathrm{Tb}-\mathrm{Co}$. Тем не менее, с учетом того, что межслойная связь пропорциональна магнитным моментам взаимодействующих слоев [2], заранее нельзя исключать и возможную активную роль подрешетки $\mathrm{Tb}$, принимая во внимание, что при низких температурах ее магнитный момент заметно превосходит момент подрешетки Со (рис. 2, a), следовательно, может играть основную роль в межслойном взаимодействии. С учетом того, что при изменении температуры от 5 до $200 \mathrm{~K}$ величина $j$ не уменьшилась и слабо изменилась, а магнитный момент подрешетки Со остается почти неизменным (рис. 2,a), можно констатировать, что обменная связь в системе $\mathrm{Tb}-\mathrm{Co} / \mathrm{FeNi}$ в основном определяется взаимодействием моментов слоя $\mathrm{FeNi}$ и подрешетки Со слоя $\mathrm{Tb}-\mathrm{Co}$. Строго говоря, полного совпадения величин $j$ трудно ожидать, так как величина $H_{\text {ex }}$ определяется особенностями формирования межслойной магнитной границы, а они заметно различаются при рассматриваемых температурах. При нагреве до $200 \mathrm{~K}$ не только заметно уменьшается намагниченность слоя Тb-Co, но и его магнитная анизотропия [19], что способствует более интенсивному проникновению межслойной магнитной границы в слой $\mathrm{Tb}-\mathrm{Co}$. Следует также отметить, что величина $j$ в системе $\mathrm{Tb}-\mathrm{Co} / \mathrm{FeNi}$ превосходит аналогичную величину для системы $\mathrm{FeMn} / \mathrm{FeNi}$ по меньшей мере на порядок [6,23].

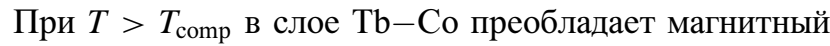
момент Сo, который, как и суммарный магнитный момент слоя, выстраивается вдоль направления внешнего магнитного поля, в отсутствии внешнего магнитного поля магнитные моменты слоев $\mathrm{Tb}-\mathrm{Co}$ и $\mathrm{FeNi}$ оказываются упорядочены ферромагнитно. Смена преобладающей магнитной подрешетки в слое $\mathrm{Tb}-\mathrm{Co}$ позволяет ожидать изменение знака обменного смещения $[2,24]$, однако на эксперименте наблюдается только перемагничивание двухслойной пленки $\mathrm{Tb}-\mathrm{Co} / \mathrm{FeNi}$ как единого целого (рис. 3,d). Это связано с тем, что в „спиновых пружинах“ послойное перемагничивание слоев наблюдается только при условии, что толщина магнитожесткого слоя примерно в два раза превышает ширину доменной стенки $\delta_{\mathrm{h}}$, которая может сформироваться в данном слое [21]. Оценка с помощью известного выражения

$$
\delta_{\mathrm{h}}=\left(A_{\mathrm{h}} / K_{\mathrm{h}}\right)^{1 / 2}
$$

где $A_{\mathrm{h}}$ - константа обменного взаимодействия, $K_{\mathrm{h}}-$ константа анизотропии магнитожесткого слоя, дает для слоя $\mathrm{Tb}-\mathrm{Co}$ величину $\delta_{\mathrm{h}}=14 \mathrm{~nm}$. Таким образом, в нашем случае толщина слоя $\mathrm{Tb}-\mathrm{Co}$, видимо, еще не превышает критической величины, при которой возможно послойное перемагничивание двухслойной пленочной структуры. Коэрцитивную силу такой ферромагнитно связанной двухслойной пленки можно оценить, используя выражение

$$
H_{c}=H_{\mathrm{ch}} t_{\mathrm{h}} /\left(t_{\mathrm{h}}+\left(M_{s} / M_{\mathrm{h}}\right) t_{s}\right)
$$

где $H_{\mathrm{ch}}$ - коэрцитивная сила однослойной магнитожесткой пленки толщиной $t_{\mathrm{h}}, M_{s}$ и $M_{\mathrm{h}}-$ намагниченности магнитомягкого и магнитожесткого слоев, $t_{s}$ - толщина магнитомягкого слоя [25]. При использовании параметров наших слоев $\mathrm{Tb}-\mathrm{Co}$ и $\mathrm{FeNi}$ расчетная величина $H_{c} \approx 300$ Ое удовлетворительно соотносится с экспериментальной величиной $H_{c}=480$ Ое. Таким образом, при $T>T_{\text {comp }}$ слоя $\mathrm{Tb}-\mathrm{Co}$ система $\mathrm{Tb}-\mathrm{Co} / \mathrm{FeNi}$ ведет себя как обычная ферро-/ферромагнитная обменно-связанная система при толщине магнитожесткого слоя, не превосходящей критическую величину.

\section{4. Заключение}

В работе продемонстрировано, что исследованные в широком интервале температур обменно-связанные ферри-/ферромагнитные структуры $\mathrm{Tb}-\mathrm{Co} / \mathrm{FeNi}$ ведут себя как „спиновые пружины“, состоящие из магнитожесткого и магнитомягкого ферромагнитных слоев. При температуре $5 \mathrm{~K}$ межслойная магнитная неоднородность типа доменной границы формируется в слое $\mathrm{FeNi}$ и все 
более интенсивно проникает в слой $\mathrm{Tb}-\mathrm{Co}$ при повышении температуры. Энергия Зеемана ферримагнитного слоя $\mathrm{Tb}-$ Со вблизи его $T_{\text {comp }}$ становится меньше, чем у слоя $\mathrm{FeNi}$, что приводит к смене последовательности перемагничивания слоев. Межслойное обменное взаимодействие в системе $\mathrm{Tb}-\mathrm{Co} / \mathrm{FeNi}$ в основном определяется взаимодействием моментов слоя $\mathrm{FeNi}$ и подрешетки Со слоя $\mathrm{Tb}-\mathrm{Co}$. При этом величина константы поверхностного межслойного взаимодействия в структуре $\mathrm{Tb}-\mathrm{Co} / \mathrm{FeNi}$ значительно превосходит аналогичный параметр для широко используемой системы $\mathrm{FeMn} / \mathrm{FeNi}$. Невозможность экспериментального наблюдения смены знака обменного смещения при переходе через температуру компенсации слоя $\mathrm{Tb}-\mathrm{Co}$, обусловлена тем, что

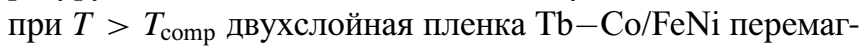
ничивается как единое целое. Подбор толщин и состава слоев позволяет варьировать особенности перемагничивания системы $\mathrm{Tb}-\mathrm{Co} / \mathrm{FeNi}$ как возможной составной части функциональных устройств спинтроники.

\section{Финансирование работы}

Работа выполнена при финансовой поддержке РНФ в рамках научного проекта № 18-72-10044.

\section{Конфликт интересов}

Авторы заявляют, что у них нет конфликта интересов.

\section{Список литературы}

[1] R.L. Stamps. J. Phys. D 33, R247 (2000).

[2] Г.И. Фролов, В.Ю. Яковчук, В.А. Середкин, Р.С. Исхаков, С.В. Столяр, В.В. Поляков. ЖТФ 75, 69 (2005).

[3] В.О. Васьковский, А.В. Свалов, К.Г. Балымов, Н.А. Кулеш. ФМM 113, 908 (2012).

[4] C. Vogler, M. Heigl, A.-O. Mandru, B. Hebler, M. Marioni, H.J. Hug, M. Albrecht, D. Suess. Phys. Rev. B 102, 014429 (2020).

[5] W.C. Cain, W.H. Meiklejohn, M.H. Kryder. J. Appl. Phys. 61, 4170 (1987).

[6] J. Nogués, I.K. Schuller. J. Magn. Magn. Mater. 192, 203 (1999).

[7] P. Chaudhari, J.J. Cuomo, R.J. Gambino. Appl. Phys. Lett. 22, 337 (1973).

[8] S. Mangin, F. Montaigne, A. Schuhl. Phys. Rev. B 68, 140404(R) (2003).

[9] S. Mangin, T. Hauet, Y. Henry, F. Montaigne, E.E. Fullerton. Phys. Rev. B 74, 024414 (2006).

[10] T. Hauet, S. Mangin, F. Montaigne, J.A. Borchers, Y. Henry. Appl. Phys. Lett. 91, 022505 (2007).

[11] R. Hasegawa, B.E. Argyle, L.-J. Tao. AIP Conf. Proc. 24, 110 (1975).

[12] B. Dieny, V.S. Speriosu, S.S.P. Parkin, B.A. Gurney, D.R. Wilhoit, D. Mauri. Phys. Rev. B 43, 1297 (1991).

[13] A. Hirohata, K. Yamada, Y. Nakatani, I.-L. Prejbeanu, B. Diény, Ph. Pirro, B. Hillebrands. J. Magn. Magn. Mater. 509, 166711 (2020).
[14] A. Hubert, R. Schäfer. Magnetic domains. The Analysis of Magnetic Microstructures. Springer, Berlin (1998). 696 p.

[15] G. Asti, M. Solzi, M. Ghidini, F.M. Neri. Phys. Rev. B 69, 174401 (2004).

[16] J. McCord, B. Erkartal, T. von Hofe, L. Kienle, E. Quandt, O. Roshchupkina, J. Grenzer. J. Appl. Phys. 113, 073903 (2013).

[17] В.П. Кравчук, Д.Д. Шека. ФТТ 49, 1834 (2007).

[18] C.-C. Lin, C.-H. Lai, D.H. Wei, Y.J. Hsu, H.-P.D. Shieh. J. Appl. Phys. 95, 6846 (2004).

[19] В.О. Васьковский, К.Г. Балымов, А.В. Свалов, Н.А. Кулеш, Е.А. Степанова, А.Н. Сорокин. ФТТ 53, 2161 (2011).

[20] E. Goto, N. Hayashi, T. Miyashita, K. Nakagawa. J. Appl. Phys. 36, 2951 (1965).

[21] E.E. Fullerton, J.S. Jiang, S.D. Bader. J. Magn. Magn. Mater. 200, 392 (1999).

[22] D. Chumakov, R. Schäfer, D. Elefant, D. Eckert, L. Schultz, S.S. Yan, J.A. Barnard. Phys. Rev. B 66, 134409 (2002).

[23] A.V. Svalov, G.V. Kurlyandskaya, V.N. Lepalovskij, P.A. Savin, V.O. Vas'kovskiy. Superlat. Microstruct. 83, 216 (2015).

[24] A.V. Svalov, E.V. Kudyukov, V.N. Lepalovskij, A.N. Gorkovenko, E.A. Stepanova, A. Larrañaga, G.V. Kurlyandskaya, V.O. Vas'kovskiy. Curr. Appl. Phys. 23, 68 (2021).

[25] Г.И. Фролов, С.Я. Кипарисов, В.А. Середкин, К.П. Полякова, Г.С. Патрин, В.С. Жигалов, А.Д. Балаев. Письма в ЖТФ 40, 28 (2014).

Редактор К.В. Емцев 